Figure 2. (A) Proportion of Patients Reporting Improvements $2 M C I D$ and (B) Scores 2 Age- And Gender-Matched Normative Values at Week 12
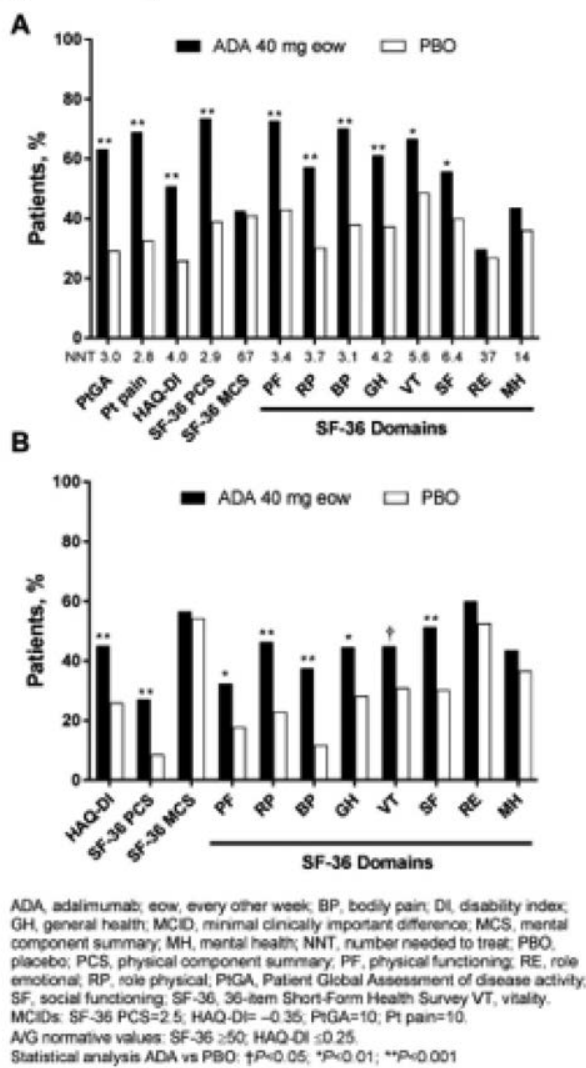

Disclosure of Interests: Vibeke Strand Consultant of: AbbVie, Amgen, Biogen, Celltrion, Consortium of Rheumatology Researchers of North America, Crescendo Bioscience, Eli Lilly, Genentech/Roche, GlaxoSmithKline, Hospira, Janssen, Merck, Novartis, Pfizer, Regeneron Pharmaceuticals, Inc., Sanofi, UCB, Pankaj Patel Shareholder of: AbbVie, Employee of: AbbVie, Naijun Chen Shareholder of: AbbVie Inc, Employee of: AbbVie Inc, Elizabeth Lesser Shareholder of: AbbVie Inc, Employee of: AbbVie Inc

DOI: 10.1136/annrheumdis-2020-eular.1254

\section{AB0836 PREVALENCE AND DETERMINANTS OF FATIGUE IN PSORIATIC ARTHRITIS IN AN ASIAN POPULATION}

\section{J. S. Q. Tan ${ }^{1,2}$, W. Fong ${ }^{1,3}$, Y. H. Kwan ${ }^{3}$, Y. Y. Leung ${ }^{1,3} .{ }^{1}$ Singapore General} Hospital, Rheumatology and Immunology, Singapore, Singapore; ${ }^{2}$ Yong Loo Lin School of Medicine, Singapore, Singapore; ${ }^{3}$ Duke-NUS Medical School, Singapore, Singapore

Background: Fatigue is one of the core domains to be measured in all clinical trials for psoriatic arthritis (PsA). Studies of fatigue in PsA in Asia are scarce. Objectives: To describe the prevalence and evaluate the factors associated with fatigue in PsA patients within a multi-ethnic Asian population.

Methods: We used data from the PRESPOND registry for PsA patients attending an outpatient clinic of a tertiary institution in Singapore. Demographics data and disease characteristics were evaluated. Fatigue was assessed by question 1 of BASDAI (BASDAI-F) and the vitality domain of SF-36 (SF-36 VT).

Results: 131 patients $(50.4 \%$ men, $63.4 \%$ Chinese, median PsA duration 1.78 years) with completed data for fatigue were included. The median (IQR) tender and swollen joint count was 2 (5) and 1 (3) respectively. 45 patients $(34 \%)$ experienced high fatigue (defined by BASDAI-F $\geq 6 / 10^{1,2}$ ). 5 clusters of factors were identified using principal component analysis that explained $66.2 \%$ of the variance of all factors, which mapped to disease activity, disease chronicity, demographics (ethnicity and gender), and BMI (Figure 1). Of these, disease activity and chronicity were significantly associated with BASDAI-F and SF-36 VT. In a multivariate analysis, back pain, peripheral joint pain and patient global assessment were associated with BASDAI-F, whereas peripheral joint pain, HAQ-DI, age and BMI were associated with SF-36 VT (Table 1).
Table 1. Multivariable analysis for variables associated with fatigue

\begin{tabular}{|c|c|c|c|c|c|c|c|c|}
\hline & BASDAI- & & & & $\begin{array}{c}\text { SF-36 } \\
\text { VT }\end{array}$ & & & \\
\hline & $b$ & $95 \% \mathrm{Cl}$ & $\beta$ & $p$ & $b$ & $95 \% \mathrm{Cl}$ & $\beta$ & $p$ \\
\hline Back pain $(0-10)$ & 0.335 & $\begin{array}{l}(0.180 \\
0.490)\end{array}$ & 0.356 & $<0.001$ & - & 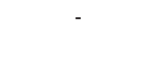 & - & - \\
\hline $\begin{array}{l}\text { Peripheral joint } \\
\text { pain }(0-10)\end{array}$ & 0.027 & $\begin{array}{l}(0.012 \\
0.042)\end{array}$ & 0.268 & 0.001 & -2.296 & $(-3.410,-1.182)$ & -0.320 & $<0.001$ \\
\hline PGA $(0-100)$ & 0.211 & $\begin{array}{l}(0.061, \\
0.361)\end{array}$ & 0.236 & 0.006 & - & - & - & - \\
\hline HAQ-DI (0-3) & - & - & - & - & -12.74 & $(-17.97,-7.51)$ & -0.386 & $<0.001$ \\
\hline Age, y & - & - & - & - & 0.260 & $(0.065,0.456)$ & 0.179 & 0.009 \\
\hline $\mathrm{BMI}, \mathrm{kg} / \mathrm{m}^{2}$ & - & - & - & - & -0.644 & $(-1.183,-0.105)$ & -0.165 & 0.020 \\
\hline
\end{tabular}

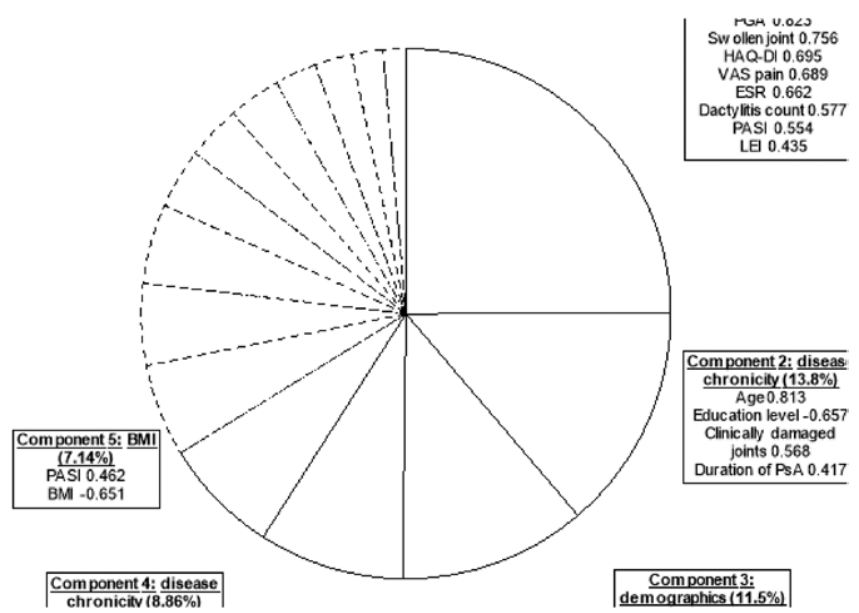

Figure 1. Principal component analysis with 5 components and residuals (in dotted lines). Only factor loadings with magnitudes greater than 0.40 are shown.

Conclusion: PsA-associated fatigue is prevalent in this Asian PsA cohort and is associated with disease activity and chronicity.

References:

[1] Gudu T, Etcheto A, de Wit M, Heiberg T, Maccarone M, Balanescu A, et al. Fatigue in psoriatic arthritis - a cross-sectional study of 246 patients from 13 countries. Joint Bone Spine. 2016;83(4):439-43.

[2] Walsh JA, McFadden ML, Morgan MD, Sawitzke AD, Duffin KC, Krueger GG, et al. Work productivity loss and fatigue in psoriatic arthritis. J Rheumatol. 2014;41(8):1670-4.

Disclosure of Interests: Joel Shi Quan Tan: None declared, Warren Fong Consultant of: Abbvie, Janssen, Novartis, Speakers bureau: Abbvie, Janssen, Novartis, Yu Heng Kwan: None declared, Ying Ying Leung Speakers bureau: Novartis, Janssen, Eli Lilly

DOI: 10.1136/annrheumdis-2020-eular.2068

\section{AB0837 ITCH AS THE MAJOR MEDIATOR OF THE EFFECT OF TOFACITINIB ON HEALTH-RELATED QUALITY OF LIFE IN PSA: A MEDIATION ANALYSIS}

P. C. Taylor ${ }^{1}$, A. G. Bushmakin², J. C. Cappelleri², P. Young ${ }^{3}$, R. Germino ${ }^{4}$, J. F. Merola ${ }^{5}$, G. Yosipovitch ${ }^{6}$. ${ }^{1}$ University of Oxford, Oxford, United Kingdom; ${ }^{2}$ Pfizer Inc, Groton, United States of America; ${ }^{3}$ Pfizer Inc, Collegeville, United States of America; ${ }^{4}$ Pfizer Inc, New York, United States of America; ${ }^{5}$ Harvard Medical School, Boston, United States of America; ${ }^{6}$ University of Miami, Miami, United States of America

Background: PsA is a chronic, systemic inflammatory disease with signs and symptoms across multiple domains, including cutaneous manifestations, which can impact health-related quality of life (HQL ). Tofacitinib is an oral Janus kinase inhibitor for the treatment of PsA. In two Phase 3 randomised studies, patients (pts) with active PsA treated with tofacitinib experienced greater improvements in various dermatologic endpoints, compared with placebo. As pruritus is a bothersome symptom of skin disease in pts with PsA, we sought to determine how tofacitinib affects HQoL via clinical improvements in skin symptoms including itch. Objectives: To determine the relationships between tofacitinib treatment, dermatologic symptoms and pt-reported HQoL related to skin disease in PsA. Methods: Analyses used data (mean scores from Months 1 and 3) from two Phase 3 studies (OPAL Broaden [NCT01877668]; OPAL Beyond [NCT01882439]) of pts with active PsA treated with tofacitinib $5 \mathrm{mg}$ twice daily or placebo; pts 